\title{
A Simple Robust Link Between American Puts and Credit Insurance
}

\author{
Peter Carr ${ }^{\mathrm{a}, \mathrm{b} *}$ Liuren $\mathrm{Wu}^{\mathrm{c} \dagger}$

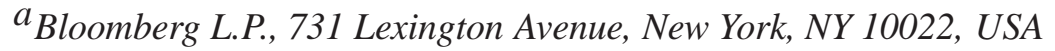 \\ ${ }^{b}$ Courant Institute, New York University, 251 Mercer Street, New York, NY 10012, USA \\ ${ }^{c}$ Baruch College, Zicklin School of Business, One Bernard Baruch Way, New York, NY 10010, USA
}

This version: May 7, 2008; First draft: September 25, 2007

\begin{abstract}
We develop a simple robust link between equity out-of-the-money American put options and a pure credit insurance contract on the same reference company. Assuming that the stock price stays above a barrier $B>0$ before default but drops and remains below a lower barrier $A<B$ after default, we show that the spread between two co-terminal American put options struck within the default corridor $[A, B]$ scaled by their strike difference replicates a standardized credit insurance contract that pays one dollar at default whenever the company defaults prior to the option expiry and zero otherwise. Given the presence of the default corridor, this simple replicating strategy is robust to the details of pre- and post-default stock price dynamics, interest rate movements, and default risk fluctuations. We use quotes on American puts to infer the value of the credit insurance contract and compare it to that estimated from the credit default swap spreads. Collecting data on several companies, we identify strong co-movements between the credit insurance values inferred from the two markets. We also find that deviations between the two estimates cannot be fully explained by common variables used for explaining American put values, such as the underlying stock price and stock return volatility, but the cross-market deviations can predict future movements in American puts.
\end{abstract}

JEL Classification: C13; C51; G12; G13.

Keywords: Stock options; American puts; unit recovery claims; credit default swaps; default probabilities.

\footnotetext{
We are grateful to Yakov Amihud, Menachem Brenner, Sanjay Dasgupta, Darrell Duffie, Bruno Dupire, Robert Engle, Stephen Figlewski, Bjorn Flesaker, Eric Ghysels, Haitao Li, Ziqiang Liu, Dilip Madan, Eric Rosenfeld, Ian Schaad, Marti Subrahmanyam, Serge Tchikanda, Andrea Vedolin, Arun Verma, Yan Wang, Robert Whitelaw, and seminar participants at Baruch College, Bloomberg, JP Morgan, and New York University for discussions and comments. We welcome comments, including references that we have inadvertently missed.

${ }^{*}$ Tel.: +1-212-617-5056; fax: +1-917-369-5629. E-mail address: pcarr4@bloomberg.com.

${ }^{\dagger}$ Tel.: +1-646-312-3509; fax: +1-646-312-3451. E-mail address: liuren_wu@ baruch.cuny.edu.
} 


\section{Introduction}

The equity and debt markets are inherently linked. In a classic paper, Merton (1974) treats equity as a call option on the firm's asset value. Under this structural modeling approach, the corporate bond credit spread becomes a function of financial leverage and firm asset volatility. The financial leverage links equity to debt and relates firm volatility to equity volatility. ${ }^{1}$ In another classic paper, Merton (1976) recognizes the direct impact of corporate default on the stock price process and assumes that the stock price jumps to zero and stays there upon the random arrival of a default event. ${ }^{2}$ Empirically, many studies have also linked corporate credit spreads to the firm's financial leverage, stock return realized volatility, stock option implied volatility, and stock option implied volatility skews across different strike prices. ${ }^{3}$

In this paper, we propose a new, simple, and robust link between equity out-of-the-money American put options and a credit insurance contract on the same reference company. The link is established under a general class of stock price dynamics. The key assumption we make is that the stock price is bounded below by a strictly positive barrier $B>0$ before default, but drops below a lower barrier $A<B$ at default, and stays below $A$ thereafter. The range $[A, B]$ defines a default corridor in which the stock price can never reside. Given the existence of the default corridor, we show that the spread between any two American put options of the same maturity and with strike prices falling within the default corridor replicates a pure credit insurance contract that pays off when and only when the company defaults prior to the option expiry.

Early structural models often make the explicit assumption that a company defaults when the firm value falls below the debt value. Under such assumptions, the equity would be worth zero right before default and stay at zero afterwards. There would be no default corridor. Nevertheless, more recent studies recognize the strategic nature of the default event and find that both equity holders and debt holders can have incentives to

\footnotetext{
${ }^{1}$ Various modifications and extensions on the debt structure, default triggering mechanism, firm value dynamics, and implementation procedures have been proposed in the literature. Prominent examples include Black and Cox (1976), Geske (1977), Ho and Singer (1982), Ronn and Verma (1986), Titman and Torous (1989) Kim, Ramaswamy, and Sundaresan (1993), Longstaff and Schwartz (1995), Leland (1994, 1998), Anderson and Sundaresan (1996), Anderson, Sundaresan, and Tychon (1996), Leland and Toft (1996), Briys and de Varenne (1997), Mella-Barral and Perraudin (1997) Garbade (1999), Fan and Sundaresan (2000), Duffie and Lando (2001), Goldstein, Ju, and Leland (2001), Zhou (2001), Acharya and Carpenter (2002), Huang and Huang (2003), Hull, Nelken, and White (2004), Bhamra, Kuehn, and Strebulaev (2007), Buraschi, Trojani, and AndreaVedolin (2007), Chen, CollinDufresne, and Goldstein (2008), and Cremers, Driessen, and Maenhout (2008).

${ }^{2}$ Extensions and estimations of the jump-to-default models include Carr and Wu (2005), Carr and Linetsky (2006), and Le (2007).

${ }^{3}$ Examples include Carey (1998), Pedrosa and Roll (1998), Bevan and Garzarelli (2000), Frye (2000), Collin-Dufresne, Goldstein, and Martin (2001), Delianedis and Geske (2001), Elton, Gruber, Agrawal, and Mann (2001), Aunon-Nerin, Cossin, Hricko, and Huang (2002), Bangia, Diebold, Kronimus, Schagen, and Schuermann (2002), Capmbell and Taksler (2003), Cremers, Driessen, Maenhout, and Weinbaum (2004) Ericsson, Jacobs, and Oviedo-Helfenberger (2004), Hilscher (2004), Consigli (2004), Vassalou and Xing (2004). Altman, Brady, Resti, and Sironi (2005), Bakshi, Madan, and Zhang (2006), Zhang, Zhou, and Zhu (2006), Berndt and Ostrovnaya (2007), Cao, Yu, and Zhong (2007), and Wu and Zhang (2008).
} 
induce or force bankruptcy well before the equity value completely vanishes. Theoretical work on strategic default includes Leland (1994), Leland and Toft (1996), Anderson and Sundaresan (1996), Mella-Barral and Perraudin (1997), Fan and Sundaresan (2000), Goldstein, Ju, and Leland (2001), Broadie, Chernov, and Sundaresan (2007), and Hackbarth, Hennessy, and Leland (2007). In an empirical paper, Carey and Gordy (2007) find empirical support for active strategic behaviors from private debt holders in setting the endogenous asset value threshold below which corporations declare bankruptcy. In particular, they find that private debt holders often find it optimal to force bankruptcy well before the equity value vanishes. Our specification of the strictly positive upper barrier $B$ is in line with such evidence and the strategic default literature. On the other hand, the sudden drop in equity value from above $B$ to below $A$ at the time of default can come from several sources, including deadweight losses such as legal fees and liquidation costs associated with the bankruptcy process. In addition, when forced to liquidate, equity holders lose the option value of future risky projects. These losses can generate a sudden drop in the equity value that defines our default corridor.

Given the presence of the default corridor and the availability of two American put options of the same maturity $T$ struck within the default corridor, $A \leq K_{1}<K_{2} \leq B$, a simple spread between the two American put options scaled by the strike distance, $U(t, T) \equiv\left(P_{t}\left(K_{2}, T\right)-P_{t}\left(K_{1}, T\right)\right) /\left(K_{2}-K_{1}\right)$, replicates a standardized credit insurance contract that pays one dollar at default whenever the company defaults prior to the option expiry and zero otherwise. Without default, the stock price stays above $K_{2}$, and neither put options will be exercised as they have zero intrinsic value. If default occurs prior to the option expiry, the stock price falls below $K_{1}$ and stays below thereafter. It becomes optimal to exercise both options at the default time, and the scaled American put spread nets a payoff of one dollar at the default time. As long as the default corridor exists and there are two traded American put options struck within this corridor, this simple replicating strategy holds robustly, irrespective of the details of the stock price dynamics before and after default, the interest rate dynamics, and default risk fluctuations.

We refer to this standardized credit contract as a unit recovery claim. This fundamental claim is simply a fixed-life Arrow-Debreu security paying off one dollar when the (default) event occurs, and zero otherwise. ${ }^{4}$ Our simple and robust replicating strategy suggests that we can learn the value of the unit recovery claim from the market quotes on equity American put options, which are actively traded in the U.S. on several options exchanges. In the special case in which the lower bound of the corridor is zero $(A=0)$ so that the stock price falls to zero at default, we can set $K_{1}=0$ and use a single American put option to replicate the unit recovery

\footnotetext{
${ }^{4}$ Currently, unit recovery claims are listed on the Chicago Board of Options Exchange under the name Credit Event Binary Options (CEBO) with planned maturities ranging from 1 to 10.25 years; however, trading volumes on the contracts are low low up to the time of this writing.
} 
claim, $U(t, T)=P_{t}\left(K_{2}, T\right) / K_{2}$.

In the option pricing literature, the American feature of stock options has introduced tremendous difficulty in option valuation. The problem of analytically relating American option prices to the underlying stock price dynamics is notoriously difficult. By contrast, we can value American put options struck within the default corridor in closed form under constant interest rate and default arrival rate assumptions. Furthermore, the American feature helps us in creating the unit recovery claim contract. Using two analogous European put options would create a contract that pays one dollar at the option expiry, instead of at default, when a default event occurs prior to the option expiry.

The most actively traded credit insurance contracts in the over-the-counter market are credit default swaps (CDS) written on corporate bonds. A CDS contract provides protection against credit risk. The protection buyer pays a fixed premium, often termed as the CDS spread, to the seller for a period of time. If a certain pre-specified credit event occurs, the protection buyer stops the premium payment and the protection seller pays the par value in return for the corporate bond. Assuming fixed and known bond recovery rate, ${ }^{5}$ we show that the value of the protection leg of the CDS contract is proportional to the value of the unit recovery claim, with the proportional coefficient being the loss given default. Assuming deterministic interest rates, we can also represent the value of the premium leg as a function of the unit recovery claim term structure. Reversely, with the assumption of fixed recovery and deterministic interest rates, we can strip the unit recovery claim term structure from the term structure of CDS spreads.

To empirically test the validity of the theoretical linkage, we select a list of companies that we have reliable quotes on American put options and CDS spreads from January 2005 to June 2007. From options, we synthesize at each date the value of the unit recovery claims at the longest option expiry. From the CDS data, which are quoted at fixed time to maturities from one to five years, we interpolate to obtain a CDS spread matching the option expiry and compute the corresponding unit recovery value while assuming fixed bond recovery rate and deterministic interest rates. We compare the time-series behavior of the two unit recovery value series, and find that the two series show similar average values and strong co-movements. Furthermore, when we regress the deviations between the two series against common variables used to explain American put values such as stock price and stock return volatility, we find that these variables cannot fully explain the deviations. On the other hand, the cross-market deviations predict future movements movements of both series, especially the movements of the American put options.

\footnotetext{
${ }^{5}$ Currently, swaps on default recovery rates are also actively traded over the counter. One can use such contracts to hedge away the uncertainties in bond recoveries embedded in the CDS contract.
} 
Our paper offers several new insights. First, many structural models with strategic default imply the existence of a default corridor, but the simple robust linkage that we identify in the presence of the corridor is new. Second, compared to the many linkages identified in the literature through parametric (structural or reduced-form) model specifications, our identified linkage between equity American put options and credit insurance is much simpler as it does not incur any significant computations involving Monte Carlo, Fourier transforms, or lattice constructions. Third, our linkage is also more robust as it does not depend on any particular parameterizations of pre- and post-default stock price dynamics, interest rates variations, and default risk fluctuations. Most importantly, the American put spread replicates the cash flow of the credit insurance contract. Hedging the credit insurance contract with the American put spread generates a static portfolio that is markedly different from dynamic hedging and rebalancing based on historical regression coefficients or gradients from an estimated parametric model.

The rest of the paper is structured as follows. The next section lays down the theoretical framework, under which we build the linkage between equity American put options and credit insurance. Section 3 describes the data that we use for our empirical work and the procedure that we follow to estimate the value of unit recovery claims. Section 4 compares the time-series behavior of the unit recovery claim values estimated from equity American puts and the CDS market. Section 5 offers concluding remarks and directions for future research.

\section{Theory}

Black and Scholes (1973) and Merton (1973) propose an option pricing model (henceforth the BMS model) that has since revolutionized the derivative industry. Under the BMS model, the underlying stock price follows a geometric Brownian motion. The risk-neutral stock price dynamics are

$$
S_{t}=S_{0} e^{r t+\sigma W_{t}-\frac{1}{2} \sigma^{2} t}
$$

where $\sigma$ denotes the constant instantaneous return volatility and $W_{t}$ denotes a standard Brownian motion. We assume zero dividend and constant interest rate $r$ for notional clarity. Starting from a positive level $S_{0}>0$, this stock price can never hit zero.

In what follows, we first review two generalizations of the BMS model, proposed by Merton (1976) and Rubinstein (1983), respectively. We combine the two generalizations to set up a toy example of our modeling framework, under which we can price American put options within a certain strike range analytically. We also 
illustrate how to link American put spreads to the credit insurance contract that we term unit recovery claims. Finally, we specify the general class of models under which the linkage between American put spreads and unit recovery claims remains robust.

\subsection{A tale of two generalizations}

For companies with positive default probabilities, the stock price going to zero is a definite possibility. After a company defaults, its stock price is likely to be low and it is common to assume that the stock price is in fact zero after bankruptcy. Recognizing that the underlying stock price dynamics in the BMS model are not consistent with this default-related behavior, Merton (1976) generalizes the dynamics by allowing the possibility for the stock price to jump to zero. Assuming a constant arrival rate $\lambda$ for such a jump, we can write the pre-default risk-neutral stock price dynamics as,

$$
S_{t}=S_{0} e^{(r+\lambda) t+\sigma W_{t}-\frac{1}{2} \sigma^{2} t} .
$$

We refer to this model as the Merton-Jump-to-Default (MJD) model. As the stock of a company is a limited liability asset, the MJD model realistically assumes that the stock price remains at zero after the jump time.

Under the MJD model, we can still replicate the payoff of a European call option by dynamically trading just the stock and a zero-coupon corporate bond whose value vanishes upon default. The addition of the bankruptcy state does not destroy our ability to replicate the payoff of the call option as long as we can use a zero-recovery zero-coupon corporate bond to replace the default-free bond as a hedge instrument. The reason is that the value of the target call option and the value of the stock-bond hedging portfolio both vanish upon default.

Since the payoff of the call option can be replicated, its price is uniquely determined by no arbitrage. Merton (1976) shows that the only effect on the BMS call pricing formula of using the MJD model is to cause the stock growth rate and call discount rate to both increase by the risk-neutral default arrival rate $\lambda$. The reason for these changes becomes clear once we recognize that the option pricing formula relates the call price at any future time to the contemporaneous stock price, conditioning on no prior default. The requirement that the unconditional risk-neutral expected return on the stock and the call both be the riskfree rate forces the conditional growth rate in each asset to be higher, as the values for both assets drop to zero upon default. Since each asset drops by $100 \%$ of its value, the conditional growth rate of each asset must exceed the riskless 
rate by the default arrival rate, as it is specified in equation (2).

The MJD model extends the BMS model to include bankruptcy while preserving tractability. In evaluating the validity of any extension of the BMS option pricing model, it has become common practice to use the notion of option implied volatility. The implied volatility of an option is defined as the constant volatility input that one must supply to the BMS option pricing model in order to have the BMS model value agree with a given option price. The given option price can be produced by either a model value or a market price and hence implied volatilities can likewise be produced by either the model or the market. The model implied volatility of the BMS model is invariant to strike price. In contrast, the model implied volatility of the MJD model is always decreasing in the strike price, generating what is commonly referred to as an implied volatility skew. In particular, Carr and Laurence (2006) derive the following short-maturity approximation for the implied volatility function under the MJD model,

$$
I V_{t}\left(d_{2}, T\right) \approx \sigma+\frac{N\left(d_{2}\right)}{n\left(d_{2}\right)} \sqrt{T-t} \lambda, \quad d_{2}=\frac{\ln \left(S_{t} / K\right)+r(T-t)-\frac{1}{2} \sigma^{2}(T-t)}{\sigma \sqrt{T-t}},
$$

where $N(\cdot)$ and $n(\cdot)$ denote the cumulative and the probability density functions of a standard normal variate, respectively. Under this approximation, the slope of the implied volatility skew against the standardized measure of moneyness $d_{2}$ evaluated at $d_{2}=0$ is simply $\sqrt{T-t} \lambda$ and is hence directly determined by the probability of default.

Motivated by the possibility of producing an analytically tractable European option pricing model for which implied volatilities can decrease or increase in strike, Rubinstein (1983) introduces the displaced diffusion option pricing model, henceforth the RDD model. In this model, Rubinstein relaxes the requirement in the BMS model that the state space of the underlying stock price diffusion be the whole positive real line. Specially, Rubinstein introduces a new parameter $B \in\left(-\infty, S_{0}\right)$ and suggests that the risk-neutral process for the underlying stock price be constructed by summing $B e^{r t}$ and a geometric Brownian motion,

$$
S_{t}=B e^{r t}+\left(S_{0}-B\right) e^{r t+\sigma W_{t}-\frac{1}{2} \sigma^{2} t}
$$

As a result, the state space of the underlying stock price process at any time $t$ is $\left(B e^{r t}, \infty\right)$ rather than $(0, \infty)$. When $B>0$, the stock price has a strictly positive lower bound and the option implied volatility for this model is monotonically increasing with the strike price. In particular, at short maturities, the implied volatility 
function can be approximated as,

$$
I V(K) \approx \frac{\int_{S}^{K} \frac{1}{x} d x}{\int_{S}^{K} \frac{1}{(x-B) \sigma} d x}=\frac{\ln (K / S)}{\ln (K-B) /(S-B)} \sigma,
$$

where the implied volatility starts at zero when the strike is below the lower bound and increases monotonically as the strike increases. The implied volatility converges to $\sigma$ as the strike price approaches infinity.

It is interesting to compare the two BMS generalizations: Merton's generalization introduces a scale factor $e^{\lambda t}$ on the allowed sample paths, while Rubinstein's generalization introduces a shift $B e^{r t}$. Under the MJD model, the underlying stock price has a state space of $[0, \infty)$ and the model implied volatility can only decline in strike price. Under RDD, the underlying stock price has a state space at time $t$ of $\left(B e^{r t}, \infty\right)$ and the model implied volatility can only increase with the strike when $B>0$. Neither model can produce a U-shaped relation between implied volatility and strike price, a shape that is the most commonly observed in individual stock options and is often referred to as the implied volatility smile. To generate smile-consistent dynamics, we propose to combine the two generalizations to both scale and shift the sample paths.

\subsection{Defaultable displaced diffusion: A toy example}

Before we lay out the general model specification, we start with a toy example to illustrate the ideas behind the linkage between the value spread of two American puts and a credit insurance contract. Our specification allows for both default as in the MJD model and diffusion displacement as in the RDD model. Taken together, we label the class of models that we propose as defaultable displaced diffusion, or the DDD model.

We start with the stock price $S$ following Rubinstein (1983)'s displaced diffusion over the fixed time horizon $t \in[0, T]$. The stock price process is assumed to be positively displaced, with $B \in\left(0, S_{0}\right]$. Then, we depart from Rubinstein's model by adding the possibility of a down jump in the stock price. If the stock price jumps at some time $\tau \in[0, T]$, we assume that it jumps to a deterministic recovery level $R(\tau)=A e^{-r(T-\tau)}$. Zero recovery $(A=0)$ is allowed as a special case within our specification. After the jump time $\tau$, the stock price grows deterministically at the riskfree rate $r: S_{t}=R(t)$ for $t \geq \tau$. The risk-neutral arrival rate of the jump in the stock price is assumed to be constant at $\lambda$.

To formally model the risk-neutral stock price dynamics in the toy DDD model, we use $G$ to denote a geometric Brownian motion,

$$
G_{t}=e^{\sigma W_{t}-\sigma^{2} t / 2}
$$


starting at $G_{0}=1$. The random process $G$ is a martingale started at one. We let $J$ be another martingale started at one defined by

$$
J_{t}=1\left(N_{t}=0\right) e^{\lambda t}
$$

where $N_{t}$ denotes a standard Poisson process with a constant arrival rate $\lambda$. This process drifts up at a constant growth rate of $\lambda$ and jumps to zero and stays there at a random and exponentially distributed time. We construct the risk-neutral stock price process $S$ by combining the two random processes $G$ and $J$ as

$$
S_{t-}=e^{r t}\left\{R(0)+J_{t-}\left[B-R(0)+\left(S_{0}-B\right) G_{t}\right]\right\}
$$

where the subscript $t$-denotes the pre-jump level at time $t$.

To understand this stock price process, we can rewrite it as the sum of three components,

$$
S_{t-}=R(0) e^{r t}+[B-R(0)] e^{r t} J_{t-}+\left(S_{0}-B\right) e^{r t} J_{t-} G_{t} .
$$

Each component has the form of a constant, multiplied by $e^{r t}$, and then a martingale. Therefore, each component can be interpreted as the time- $t$ value resulting from investing the constant in an asset whose initial price is one. In this sense, we are attributing the equity value of a firm to returns from three types of investments. The first type is a riskless cash reserve defined by the deterministic and non-negative process $R(t)=R(0) e^{r t}$. Zero riskless cash reserve would result in zero equity recovery upon default. The second type is a defaultable risky cash reserve defined by the stochastic and non-negative process $[B-R(0)] e^{r t} J_{t-}$, with the martingale $J_{t-}$ capturing the default risk. The third type of investment is a defaultable and market risky asset defined by the stochastic and non-negative process $\left(S_{0}-B\right) e^{r t} J_{t-} G_{t}$, with the martingale $G_{t}$ capturing the market, diffusion-type risk. Under the risk-neutral measure $\mathbb{Q}$, all three investments generate a risk-neutral expected return of $r$.

If we set $\lambda=0$ in the toy DDD model, the model degenerates to the positively displaced diffusion of Rubinstein (1983), for which implied volatility increases with strike. Conversely, if we set $B=0$ and assume zero equity recovery, the model degenerates to Merton (1976)'s MJD model, for which implied volatility decreases with strike. When $\lambda$ and $B$ are both positive, the implied volatility displays a smile when graphed against the strike price. This model behavior is broadly consistent with the behavior of implied volatilities obtained from market prices of listed American stock options.

Under the DDD model, $J_{t}=e^{\lambda t}$ prior to default and $G_{t}>0$. Hence, equation (9) implies that the stock 
price $S_{t}$ exceeds $B(t) \equiv R(0) e^{r t}+[B-R(0)] e^{(r+\lambda) t}$. At the default time $\tau, J_{\tau}=0$, and the stock price jumps down to the riskless cash reserve level $R(\tau) \equiv A e^{-r(T-\tau)}$. After the default, the stock price evolves risklessly according to $S_{t}=A e^{-r(T-t)}$. Since $B(t) \geq B$ and $R(t) \leq A$, the stock price process is random and at least $B$ before default occurs, $t \in[0, \tau \wedge T]$, and becomes deterministic and at most $A$ after default, $t \in[\tau, T]$. We label the region $[A, B]$ as the default corridor, within which the stock price cannot reside prior to option expiry.

\subsubsection{Transition probability density function}

Under the DDD model, the transition probability density function of the stock price can be derived in closed form. For $K>B(T)$ and $S>B(t)$, the probability density conditional on surviving to $T$ is

$$
\mathbb{Q}\left\{S_{T} \in d K \mid S_{t}=S, N_{T}=0\right\}=\frac{1}{\sqrt{2 \pi \sigma^{2}(T-t)}} \exp \left[-\frac{\ln h+\frac{1}{2} \sigma^{2}(T-t)}{2 \sigma^{2}(T-t)}\right] \frac{1}{K-A-[B-R(0)] e^{(r+\lambda) T}},
$$

with

$$
h=\frac{(K-A) e^{-(r+\lambda)(T-t)}-[B-R(0)] e^{(r+\lambda) t}}{S-\left\{R(0) e^{r t}+[B-R(0)] e^{(r+\lambda) t}\right\}} .
$$

We leave the proof to Appendix A. The risk-neutral default probability over $[t, T]$ is simply $1-e^{-\lambda(T-t)}$ and this is also the risk-neutral probability that $S_{T}=A$, given that $S_{t}>B(t)$. One can easily use these results to develop closed form formulas for European options.

\subsubsection{Pricing American put options}

To price American put options, we divide the strike prices $K$ into four regions. If the strike price is above $B$, we need to resort to finite difference methods to numerically approximate the American put value as is the case under the BMS model, the MJD model, or the RDD model. On the other hand, if the strikes are below or equal to $R(0), K \in[0, R(0)]$, the American puts are worthless because they cannot finish in the money in the DDD model as the stock price is always no lower than $R(0)$.

If the strikes fall between $K \in(R(0), A]$, at any time $t$ before default, the stock price is above $B$ and hence the strike price $K$. To define the continuation and exercise regions, let $t^{*}$ solve $A e^{-r\left(T-t^{*}\right)}=K$. If default occurs at some time $\tau$ in $\left(0, t^{*}\right), S_{\tau}<K$ and it is optimal to exercise at $\tau$. If default occurs in $\left[t^{*}, T\right], S_{\tau} \geq K$ and it is better to hold on to the American put and let it expire worthless. Therefore, for such puts, the continuation region is the union of all stock prices above $B(t)$ and the curve $R(t), t \in\left[t^{*}, T\right]$, while the exercise region is 
just the curve $R(t), t \in\left[0, t^{*}\right]$. The payoff from holding such an American put is $K-R(\tau)$ at time $\tau$ if $\tau \leq t^{*}$ and zero otherwise. Let $P_{0}(K, T)$ denote the time-0 value of an American put. By risk-neutral valuation, we have,

$$
\begin{aligned}
P_{0}(K, T) & =\mathbb{E}^{\mathbb{Q}}\left\{e^{-r \tau}[K-R(\tau)] 1\left(\tau \leq t^{*}\right)\right\}=\int_{0}^{t^{*}} \lambda e^{-\lambda t} e^{-r t}\left[K-A e^{-r(T-t)}\right] d t \\
& =\lambda\left[K \frac{1-e^{-(r+\lambda) t^{*}}}{r+\lambda}-A e^{-r T} \frac{1-e^{-\lambda t^{*}}}{\lambda}\right] .
\end{aligned}
$$

Most interesting to us is when the strike prices fall within the default corridor $K \in[A, B]$. Then, we have $t^{*}>T$. The continuation region is all stock prices above $B(t)$ and the exercise region is just the curve $R(t), t \in[0, T]$. The put value is obtained by simply replacing $t^{*}$ with $T$ in equation (12),

$$
P_{0}(K, T)=\lambda\left[K \frac{1-e^{-(r+\lambda) T}}{r+\lambda}-A e^{-r T} \frac{1-e^{-\lambda T}}{\lambda}\right]
$$

Importantly, equation (13) shows that the value of an American put struck within the default corridor depends only on the default risk of the company, but not on the market risk component of the stock price dynamics. In particular, holding fixed the default arrival rate $\lambda$, the American put value does not depend on the stock price and hence exhibits zero delta. Furthermore, the American put does not depend on the diffusion volatility $\sigma$ and hence shows zero vega when vega is defined as option value sensitivity against the diffusion volatility.

\subsubsection{Linking American put spreads to unit recovery claims}

Suppose that the market prices are available for at least two out-of-the-money American put options with a common maturity $T$ and with the strikes falling within the default corridor $[A, B]$. Let $K_{1}$ and $K_{2}$ denote the associated strike prices with $A \leq K_{1}<K_{2} \leq B$. Since $S_{t} \geq B$ prior to the default time, neither put will be exercised if the firm survives to $T$. On the other hand, if the firm defaults at some time $\tau$ before $T$, since $S_{\tau} \leq K_{1}$ and grows deterministically thereafter, both puts will be exercised at $\tau$. Let $\triangle K \equiv K_{2}-K_{1}$ and $\triangle P_{t}(T) \equiv P_{t}\left(K_{2}, T\right)-P_{t}\left(K_{1}, T\right)$, where $P_{t}\left(K_{1}, T\right)$ and $P_{t}\left(K_{2}, T\right)$ are the two observable put option prices at

time $t$. Suppose that an investor buys $\frac{1}{\Delta K}$ units of the $K_{2}$ put and writes an equal number of the $K_{1}$ put, the time-t cost of this position is $\triangle P_{t}(T) / \triangle K$, which we refer to as the American put spread.

If no default occurs prior to expiry $(\tau>T)$, the American put spread expires worthless. If $\tau \leq T$, the American put spread pays out one dollar so long as both parties behave optimally. Furthermore, so long as 
the American put prices are consistent with optimal behavior as is usually assumed, these prices can be used to value credit derivatives.

To illustrate this point, consider a unit recovery claim, which pays one dollar at $\tau$ if $\tau \leq T$ and zero otherwise. Let $U(t, T)$ denote the time- $t$ value of this claim. In the toy DDD model, this value is

$$
U(t, T)=\mathbb{E}_{t}^{\mathbb{Q}}\left[e^{-r \tau} 1(\tau<T)\right]=\int_{t}^{T} \lambda e^{-(r+\lambda) s} d s=\lambda \frac{1-e^{-(r+\lambda)(T-t)}}{r+\lambda} .
$$

Comparing the value of the unit recovery claim to the risk-neutral default probability over the same horizon,

$\mathbb{D}(t, T)=\mathbb{E}_{t}^{\mathbb{Q}}[1(\tau<T)]=1-e^{-\lambda(T-t)}$, which can be regarded as the forward price of one dollar paid at expiry upon default up to expiry, we obtain the following ranking,

$$
U(t, T) \leq \mathbb{D}(, T) \leq e^{r(T-t)} U(t, T), \quad r \geq 0 .
$$

The risk-neutral default probability is higher than the present value of the unit recovery claim but lower than the forward price of the unit recovery claim given the payment timing differences.

Since the unit recovery claim and the put spread have exactly the same payoff, no-arbitrage dictates that they should be valued the same. Thus, if the market prices of the two American puts $P_{t}\left(K_{2}, T\right)$ and $P_{t}\left(K_{1}, T\right)$ are available, we can infer the value of the unit recovery claim from the prices of the two American put options,

$$
U^{o}(t, T)=\frac{P_{t}\left(K_{2}, T\right)-P_{t}\left(K_{1}, T\right)}{K_{2}-K_{1}}
$$

where we use the subscript $o$ to denote the information source as from options.

\subsection{Defaultable displaced diffusion: The general specification}

The toy DDD model places strong restrictions on the stock price dynamics to show clearly the tight linkage between American put spreads and default contingent claims. In this subsection, we show that the fundamental linkage as shown in equation (16) remains valid, even if we relax the assumptions of the toy DDD model substantially. In particular, we can generalize the model along four major dimensions.

- Random Interest Rates: In the toy DDD model, the riskfree interest rate is fixed as a constant. In the general specification, we allow the spot interest rate $r$ to be a nonnegative stochastic process. As a result, there exists a money market account whose initial balance is one and whose balance at time $t \in[0, T]$ is 
given by $\mathcal{B}_{t} \equiv e^{\int_{0}^{t} r_{s} d s}$. No arbitrage dictates that there exists a risk-neutral probability measure $\mathbb{Q}$ under which the gains process from any admissible trading strategy deflated by $\mathcal{B}$ is a martingale.

- Random Stock Recovery: In the toy DDD model, the stock price evolves randomly above $B$ prior to default, and the recovery value $R(t)$ evolves deterministically below a level $A<B$ afterwards. In the general DDD class of stochastic processes, the stock price can be random at the default time and afterwards, but it must evolve below a barrier $A<B$ in any post-default period $t \in[\tau, T]$. To define these post-default dynamics, let $(A, B)$ be the default corridor with $A \geq 0$ and $B<S_{0}$. Let $R_{t}$ be the spot price of an asset with support $[0, A]$ over $[0, T]$. We may write its stochastic differential equation as:

$$
d R_{t}=r_{t} R_{t} d t+d M_{t}^{R}, t \in[0, T]
$$

where $M^{R}$ is a $\mathbb{Q}$ martingale. We simply set $S_{t}=R_{t}$ in any post-default period $t \in[\tau, T]$.

- Stochastic Default Arrival: In the toy DDD model, the risk-neutral default arrival rate is constant. In the generalization, the risk-neutral default arrival rate $\lambda$ is a nonnegative stochastic process. We define $J_{t} \equiv 1\left(N_{t}=0\right) e^{\int_{0}^{t} \lambda_{s} d s}$ where $N$ is now a counting process. We note that $J$ is a stochastic exponential since it solves:

$$
d J_{t}=-J_{t-}\left[d N_{t}-\lambda_{t} d t\right] .
$$

Furthermore since $N_{t}-\int_{0}^{t} \lambda_{s} d s$ is a martingale, so is $J$. We require that the martingale $J$ be independent of the process $R$.

- Stochastic Volatility and Jumps: In the toy DDD model, the market risk driver is a geometric Brownian motion, denoted as $G_{t}$. In the general specification, we allow the market risk driver $G$ to be the stochastic exponential of a martingale $M^{G}$, i.e., $G_{t}=\mathcal{E}\left(M^{G}\right)$. As a result, $G$ still starts at one and is still a martingale since

$$
d G_{t}=G_{t-} d M_{t}^{G}
$$

The process $G$ is now allowed to jump, but we assume that jumps in $M^{G}$ are bounded below by -1, so that $G$ is nonnegative. We furthermore require that the martingale $G$ be independent of the martingale $J$. In contrast, $G$ can depend on $r, \lambda$, and $R$.

With these four dimensions of generalization, we construct the stock price process as

$$
S_{t}=\left(1-J_{t}\right) R_{t}+e^{\int_{0}^{t} r_{s} d s} J_{t}\left[B+\left(S_{0}-B\right) G_{t}\right]
$$


where $R_{0-} \equiv R_{0}$. We can again express $S$ as the sum of three stochastic processes,

$$
S_{t}=R_{t}-J_{t} R_{t}+e^{\int_{0}^{t} r_{s} d s} J_{t}\left[B+\left(S_{0}-B\right) G_{t}\right], \quad t \in[0, T)
$$

For $t \in[0, \tau \wedge T]$, the first term $R_{t}$ is clearly an asset price process, as indicated in equation (17). Since the martingale $J$ is a stochastic exponential and is orthogonal to $R$, the product $J R$ is also an asset price process for $t \in[0, \tau \wedge T]$. Since the martingales $J$ and $G$ are orthogonal, the process $J_{t}\left[B+\left(S_{0}-B\right) G_{t}\right]$ is also a martingale. As a consequence, the last term in (21) is an asset price process. It follows that $S$ is also an asset price process for $t \in[0, \tau \wedge T]$. Since $N_{t}=0$ and $J_{t}=e^{\int_{0}^{t} \lambda_{s} d s}$ prior to default, the stock price dynamics over $t \in[0, \tau \wedge T)$ can also be written as,

$$
S_{t}=R_{t}\left[1-e^{\int_{0}^{t} \lambda_{s} d s}\right]+e^{\int_{0}^{t}\left(r_{s}+\lambda_{s}\right) d s}\left[B+\left(S_{0}-B\right) G_{t}\right]
$$

The stochastic differential equation that governs the stock price process prior to default becomes,

$$
d S_{t}=\left(r_{t}+\lambda_{t}\right)\left(S_{t}-R_{t}\right) d t+r_{t} R_{t} d t+\left[S_{t-}-R_{t-}-J_{t-} e^{\int_{0}^{t} r_{s} d s}\left(B-R_{t}\right)\right] d M_{t}^{G}, \quad t \in[0, \tau \wedge T] .
$$

Equation (21) treats the stock as a long position in the reserve asset with price $R_{t}$, a short position in the default risky version of this asset with price $e^{\int_{0}^{t} \lambda_{s} d s} R_{t}$ prior to default, and finally a long position in an asset worth at least $e^{\int_{0}^{t}\left(r_{s}+\lambda_{s}\right) d s} B$ prior to default. Since $e^{\int_{0}^{t} r_{s} d s} \geq 1$, the latter two positions net to at least $e^{\int_{0}^{t} \lambda_{s} d s}\left(B-R_{t}\right)$ prior to default. Since $e^{\int_{0}^{t} \lambda_{s} d s} \geq 1$, the three positions are worth at least $B$ prior to default. Thus, the stock price evolves randomly above $B$ in the pre-default period $[0, \tau \wedge T]$. If the default time $\tau$ occurs at or before $T$, the stock price jumps to $R_{\tau} \in[0, A]$, and evolves as $R$ afterwards. Therefore, the default corridor $[A, B]$ remains under the generalized DDD specification.

Now, consider two American put options with a common expiry date $T$ and with the two strike prices falling within the default corridor, $A \leq K_{1}<K_{2} \leq B$. Prior to default, the stock price evolves randomly above $B$, which is above the strike prices of both options. Therefore, neither option is exercised. If default occurs at or before $T$, the stock price jumps at the default time to some random recovery level $R_{\tau}$ that is below the strike prices of both options and stays below both strikes afterwards. As a result, both American puts are optimally exercised at $\tau$. These results jointly imply that the American spread scaled by their strike distance replicates the unit recovery claim that pays one dollar when default occurs prior to option expiry and zero otherwise. 
Accordingly, the value of the unit recovery claim should be equal to the value of the scaled put spread,

$$
U^{o}(t, T)=\frac{P_{t}\left(K_{2}, T\right)-P_{t}\left(K_{1}, T\right)}{K_{2}-K_{1}}
$$

Furthermore, using American put options at different maturities, we can compute the values of the unit recovery claim from equation (24) at different maturities. If we further assume deterministic interest rates, we can strip the risk-neutral default probabilities from the term structure of unit recovery claims. Specifically, assume that the riskfree rate is a deterministic function of time $r(t)$ and let $S(t, T)$ denote the time-t price of the survival claim that pays $\$ 1$ at $T$ if no default occurs before $T$ and zero otherwise. Then, irrespective of how default occurs, no arbitrage implies that

$$
\mathcal{S}(t, T)=e^{-\int_{t}^{T} r(s) d s}-U(t, T)+\int_{t}^{T} r(s) e^{-\int_{s}^{T} r(u) d u} U(t, s) d s .
$$

The equation reflects the fact that the survival claim has the same payoff as the portfolio consisting of:

- long one default-free bond paying $\$ 1$ at $T$ and costing $e^{-\int_{t}^{T} r(s) d s}$ at time $t$.

- short one unit recovery claim maturing at $T$ and costing $U(t, T)$.

- long $r(s) e^{-\int_{s}^{T} r(u) d u} d s$ unit recovery claims for each maturity $s \in[t, T]$, with each unit costing $U(t, s)$.

If no default occurs before $T$, the default-free bond in the portfolio pays off the desired dollar, while all of the unit recovery claims expire worthless. If the default occurs before $T$, the value of the portfolio at the default time $\tau \in[t, T]$ becomes

$$
e^{-\int_{\tau}^{T} r(s) d s}-1+\int_{\tau}^{T} r(s) e^{-\int_{s}^{T} r(u) d u} d s=e^{-\int_{\tau}^{T} r(s) d s}-1+\int_{\tau}^{T} d e^{-\int_{s}^{T} r(u) d u}=0,
$$

as desired.

Once the price of the survival claim $\mathcal{S}(t, T)$ is known, the risk-neutral probability of defaulting over $[t, T]$ is,

$$
\mathbb{D}(t, T) \equiv \mathbb{Q}\{\tau<T\}=1-e^{\int_{t}^{T} r(s) d s} \mathcal{S}(t, T)=U(t, T) e^{\int_{t}^{T} r(s) d s}-\int_{t}^{T} r(s) e^{\int_{t}^{s} r(u) d u} U(t, s) d s .
$$

The risk-neutral default probability $\mathbb{D}(t, T)$ and $U(t, T) e^{\int_{t}^{T} r(s) d s}$ are both forward prices of claims that pay one dollar if default occurs before expiry. The risk-neutral default probability $\mathbb{D}(t, T)$ is lower than the forward price of the unit recovery claim $U(t, T) e^{\int_{t}^{T} r(s) d s}$ when interest rates are positive, because the payment time is 
at expiry $T$ in the former claim but $\tau \leq T$ in the latter.

\subsection{Linking unit recovery claims to CDS spreads}

The most actively traded credit contract takes the form of a credit default swap (CDS) written on corporate bonds. A CDS contract provides protection against credit risk. The protection buyer pays a fixed premium, often termed as the CDS spread, to the seller for a period of time. If a certain pre-specified credit event occurs, the protection buyer stops the premium payment and the protection seller pays the par value in return for the corporate bond.

In this section, we analyze how to use unit recovery claim values to determine the CDS spread in a fairly robust way. Let $V^{\text {prot }}(t, T)$ denote the time- $t$ value of the protection leg of a CDS contract and $R^{b}$ denote the recovery rate on the corporate bond in case of default. The protection leg pays $1-R^{b}$ at the time of default $(\tau)$ if $\tau \leq T$ and zero otherwise. The recovery rate on corporate bonds is in general not known ex ante and it can vary with different bonds and different default situations. Nevertheless, also actively traded nowadays are swaps on the recovery rate of corporate bonds on default. Thus, one can use the recovery swaps to remove the uncertainty in the bond recovery in the credit default swap contract. Assuming that the recovery rate $R^{b}$ is known and fixed, we observe that the payoff of the protection leg of the CDS is simply $1-R^{b}$ times the payoff of a unit recovery claim. No arbitrage implies that

$$
V^{\text {prot }}(t, T)=\left(1-R^{b}\right) U(t, T)
$$

To value the premium leg of a CDS contract, we let $A(t, T)$ denote the value of a defaultable annuity that pays $\$ 1$ per year continuously until the earlier of the default time $\tau$ and its maturity date $T$. We can write the annuity value as

$$
A(t, T)=\int_{t}^{T} \mathcal{S}(t, s) d s
$$

with $\mathcal{S}(t, s)$ being the prevent value of a survival claim that pays one dollar at time $s$ if $\tau>s$ and zero otherwise. Assuming that the riskfree rate is a deterministic function of time $r(t)$, we can substitute (25) into (29) to relate $A(t, T)$ to the term structure of unit recovery claims,

$$
A(t, T)=\int_{t}^{T}\left\{e^{-\int_{t}^{s} r(u) d u}-U(t, s)+\int_{t}^{s} r(u) e^{-\int_{u}^{s} r(v) d v} U(t, u) d u\right\} d s .
$$


Finally, let $k(t, T)$ denote the time- $t$ CDS spread of expiry date $T$. Assuming continuous premium payments until $\tau \wedge T,{ }^{6}$ we can represent the CDS spread as

$$
k(t, T)=\frac{V^{p r o t}(t, T)}{A(t, T)} .
$$

Assuming a known bond recovery rate $R^{b}$ implies that equation (28) can be used to relate the numerator to the unit recovery claim value $U(t, T)$. Assuming deterministic interest rates implies that equation (30) can be used to relate the denominator to a given term structure of unit recovery claims. Making both assumptions allows the CDS spread to be expressed in terms of unit recovery claim values,

$$
k(t, T)=\frac{\left(1-R^{b}\right) U(t, T)}{\int_{t}^{T}\left\{e^{-\int_{t}^{s} r(u) d u}-U(t, s)+\int_{t}^{s} r(u) e^{-\int_{u}^{s} r(v) d v} U(t, u) d u\right\} d s} .
$$

Reversely, one can numerically infer the term structure of unit recovery claims from the term structure of CDS spreads (Carr and Flesaker (2007)).

\section{Data and methodology}

To gauge the empirical validity of the simple theoretical linkage between American put spreads and credit protection, we select a list of companies. For each company, we obtain quotes both on American put options written on the company's stock and CDS spreads written on the company's corporate bond. We create unit recovery claims from the American puts and compare them to the corresponding values estimated from the CDS spreads.

The American options quotes on stocks are obtained from OptionMetrics, and the CDS spreads are obtained from Bloomberg. The stock options are exchange-listed with fixed expiry dates, the longest time to maturity ranging from one to three years. The CDS spreads are on over-the-counter contracts with fixed timeto-maturities at one, two, three, and five years. Our analysis is based on the common sample period for the two data sets from January 2005 to June 2007.

For each selected company and at each date, we estimate the unit recovery claim value from American puts at the longest option expiry. Accordingly, we interpolate the CDS spreads across fixed time to maturities

\footnotetext{
${ }^{6}$ In practice, payments are quarterly, but an accrued spread payment is netted against the default payoff when default does not occur on a CDS payment date.
} 
to obtain the CDS spread at the corresponding expiry date. We then compute the corresponding unit recovery value based on the interpolated CDS spread and the prevailing interest rates. We collect U.S. dollar LIBOR and swap rate data from Bloomberg and strip the interest rate curve based on a piece-wise constant forward assumption.

To select a list of companies with reliable quotes for both the stock options and the CDS spreads, we apply the following filtering criteria: (1) Bloomberg provides reliable CDS quotes for the company at one-, two-, and three-year maturities over our sample period. (2) OptionMetrics provides non-zero bid quotes for one or more put options struck more than one standard deviation below the stock price and maturing in more than 360 days. (3) The average CDS spread at one-year maturity over our sample period is over 30 basis points. The first two criteria guarantee that we have the required data from both markets for our comparative analysis. The third criterion generates a set of companies with significant default probabilities. For companies with very low default probabilities, the noise due to bid-ask spreads of out-of-the-money put options would swamp any default signal that these prices may possess. Based on the above criteria, we choose eight companies. Table 1 lists the tickers, the cusip numbers, and the names of the eight companies.

\subsection{Constructing unit recovery claims from American put spreads}

Our model assumes the existence of a default corridor $[A, B]$ such that the stock price evolves randomly above the corridor before default and it evolves randomly below the corridor after the default. Given knowledge of the corridor, we can choose two American put options struck within the corridor and form an American put spread that replicates a unit recovery claim. If we observe American put options across a continuum of strike prices, this corridor will reveal itself as the strike range within which the American put option prices are linear in the strike prices with the slope equal to the unit recovery value. Outside the corridor, American put option prices are usually a convex function of the strike price due to market risk (return volatility). In reality, however, American option quotes are available only at a finite number of strikes. Detecting the default corridor requires additional assumptions.

We have considered three alternative assumptions in identifying the default corridor:

A1 We assume zero equity recovery upon default $(A=0)$. Accordingly, we set $K_{1}=0$ and choose the lowest strike with non-zero bid for the American put as $K_{2}$. Then, the value of the unit recovery claim is simply the American put value at $K_{2}$ scaled by the strike, $U^{o}(t, T)=P_{t}\left(K_{2}, T\right) / K_{2}$, where $P_{t}\left(K_{2}, T\right)$ denotes the mid value of the American put option. 
A2 We assume that the two lowest strikes with non-zero bids for the American puts are both within the default corridor. Accordingly, we set the two strikes $K_{1}$ and $K_{2}$ to these two lowest strikes with nonzero bids and compute the unit recovery claim value as $U^{o}(t, T)=\left(P_{t}\left(K_{2}, T\right)-P_{t}\left(K_{1}, T\right)\right) /\left(K_{2}-K_{1}\right)$.

A3 We plot the American put mid value as a function of the strike price and estimate the convexity of the function as each strike point. We choose the strike with the lowest convexity estimate as $K_{2}$ and the adjacent lower strike as $K_{1}$ to determine the unit recovery value.

The qualitative conclusions drawn from the three alternative unit recovery claim estimates are largely the same. Assumption A1 is the simplest and it allows us to replicate the unit recovery claim using one single American put option. Using one instead of two American put options can potentially reduce the transaction costs involved in the replication. The unit recovery claim series constructed under A2 tend to contain more short-term noises. The last method often generates better results when we have a large number of strikes, but can break down and generate poor estimates when we only have a few strikes available. In what follows, we perform our analysis based on the unit recovery claim values constructed from A1, the simplest of the three methods.

\subsection{Inferring unit recovery claim values from CDS spreads}

To verify the unit recovery claim value computed from American put options, we also estimate its value from quotes on the most actively traded over-the-counter credit derivative contract, the CDS spreads.

The American options are at fixed expiry dates. The unit recovery claims that we have created from American put options have time to maturities ranging from 540 to 963 days. The over-the-counter quotes on

the CDS spreads are at fixed time to maturities at one, two, three, and five years. To estimate the corresponding unit recovery claim value from the CDS market, we first linearly interpolate the CDS spreads across maturities to obtain a CDS spread at the maturity matching the option expiry date. Then, we compute the unit recovery value from the interpolated CDS spread $k(t, T)$ by assuming fixed bond recovery rate of $40 \%\left(R^{b}=40 \%\right)$ and deterministic interest rates,

$$
U^{c}(t, T)=\lambda^{c}(t, T) \frac{1-e^{-\left(r(t, T)+\lambda^{c}(t, T)\right)(T-t)}}{r(t, T)+\lambda^{c}(t, T)}, \quad \lambda(t, T)^{c}=k(t, T) /\left(1-R^{b}\right)
$$

where $r(t, T)$ denotes the continuously compounded spot interest rate of the relevant maturity, which we strip from the LIBOR and swap rates. The superscript $c$ on the unit recovery value $U(t, T)$ reflects the fact that the 
information is from the CDS market,

\section{Results}

For each selected company, we compare the two time series of unit recovery claim values estimated from the options and the CDS markets. If our theoretical linkage is valid, we should expect that (i) the unit recovery claim value that we create from the American put options is close in magnitude to the corresponding value estimated from the CDS market; (ii) the two unit recovery claim value series show strong co-movements; and (iii) the value of the scaled American put $U^{o}(t, T)=P_{t}\left(K_{2}, T\right) / K_{2}$ is a pure credit contract and thus, once controlled for the credit risk variation, should not vary significantly with other common variables that affect option pricing such as stock price and stock return volatility.

\subsection{Summary statistics of the unit recovery claims}

Table 2 reports the summary statistics of the unit recovery claim value series $U_{t}^{c}$ and $U_{t}^{o}$, estimated from the CDS market and the American put market, respectively. The last column reports the cross-correlation estimates of the two series for each company. As they are values on the same contract but estimated from different markets, we expect the two series to have similar summary statistical behaviors and show strong co-movements. The mean values of the two series are in comparable magnitudes. The CDS market generates higher mean values for the unit recovery claim on AMR, F, and GM, but lower mean values on the other five companies. The daily autocorrelation estimates for $U_{t}^{c}$ are slightly higher than that for $U_{t}^{o}$ for all eight companies, suggesting that the values computed from the American puts contain more transitory variations.

To analyze the source of the value deviations across the two markets, we perform the following stacked regression,

$$
U_{t}^{o}-U_{t}^{c}=D_{i}-0.5033\left(U_{t}^{c}+U_{t}^{o}\right) / 2+0.0466 \ln K_{t}+e_{t}
$$

where $D_{i}$ is a matrix of intercept dummy variables accounting for potential average differences across different firms. We estimate the relation using the generalized methods of moments with the weighting matrix constructed according to Newey and West (1987) with 60 lags. The regression generates an R-squared of 85.24\%. The estimates suggest that the American puts tend to generate higher unit recovery values than that from the CDS spreads when the URC levels are low and the strike choices are high. On the other hand, the 
American put-generated URC values tend to be lower when the URC levels are high and the chosen strike levels are low.

When the unit recovery claim value is low, the American put value within the default corridor can be so low that given the discreteness of the tick size, ${ }^{7}$ market makers can put a zero bid on these options. Since we choose options with strictly non-zero bids, we can over-estimate the unit recovery value by choosing a strike above the actual default corridor. The bias is larger when the selected strike price is higher.

On the other hand, when the unit recovery claim value is high, the American put values within the default corridor are high. In this case, we may under-estimate the unit recovery claim value by assuming zerorecovery on the equity value and by setting $K_{1}=0$. For example, if the equity recovery $A$ is strictly above zero, the scaled American put option $P_{t}\left(K_{2}, T\right) / K_{2}$ will pay off $\left(K_{2}-A\right) / K_{2}$ at default when the default time is at or prior to the option expiry date. This payoff is lower than the one dollar from the unit recovery claim contract. Accordingly, the scaled American put value under-estimates the unit recovery claim value.

Furthermore, when we infer the unit recovery claim value from the CDS spreads, we make the assumption that the bond recovery rate is known and fixed at $40 \%$. If in reality the expected recovery is lower when the expected default probability is high, our fixed recovery assumption would over-estimate the unit recovery value from the CDS spread when the default probability (and hence unit recovery value) is high and underestimate the unit recovery value when the default probability is low, thus also generating the negative slope on the unit recovery claim value from the regression in (34).

\subsection{Strong co-movements between the American puts and the CDS markets}

Despite the scale differences induced by the recovery assumptions, the two series show strong co-movements. The cross-correlation estimates in the last column of Table 2 range from 0.369 for CTB to 0.941 for GM, with an average of 0.784 . The correlation estimates are particular high for companies with high average unit recovery values and hence high default probabilities.

To further analyze the co-movements of the two series for each company, we regress the American putgenerated unit recovery claim value on the CDS-generated unit recovery claim value,

$$
U_{t}^{o}=a+b U_{t}^{c}+\mathfrak{u}_{t}
$$

\footnotetext{
${ }^{7}$ The tick size is five cents for options less than three dollars and ten cents for options above three dollars. Reducing the tick size to pennies is currently under experiment through the pilot program.
} 
where regression coefficients $(a, b)$ adjust for the potential level and scale biases induced by our option strike choices and equity and bond recovery assumptions. The regression residual $\mathfrak{l}_{t}$ captures the part of the variation of the American put option $\left(U_{t}^{o}=P_{t}(K) / K\right)$ that cannot be explained by the CDS market variation. We estimate the relation using the generalized methods of moments with the weighting matrix constructed according to Newey and West (1987) with 60 lags.

Table 3 reports the coefficient estimates and $t$-statistics (in parentheses) of the regressions on the left hand side. Under the null hypothesis that the two time series $U_{t}^{o}$ and $U_{t}^{c}$ represent values on the same contract, we have that $a=0$ and $b=1$. The $t$-statistics of the coefficient estimates are computed against these two null values, respectively. The slope estimates differ for different companies, but they are all positive and vary around the null value of one. On average, the slope is below one at 0.933 and the intercept is positive at 0.016 . In addition to the possible differences induced to strike choices and recovery assumption, another source for this average bias is the well-known errors-in-variables issue: When the regressor contains noise, the slope coefficient is biased toward zero and the intercept is biased, accordingly, away from its null value.

Table 3 also reports on the right hand side the R-squared of the regressions $\left(R^{2}\right)$ as well as the daily autocorrelation (Auto), minimum (Min), and maximum (Max) of the regression residuals. The high R-squared estimates suggest that a large proportion of the variation in the American puts $\left(U_{t}^{o}\right)$ can be explained by the CDS market variation $\left(U_{t}^{c}\right)$. Furthermore, the regression residuals show lower persistence than the original series $U_{t}^{o}$, and the minimum and maximum of the residuals lie relatively symmetric around zero.

To visualize the co-movements, Figure 1 plots the time series of the explained credit risk variation $\widehat{U}_{t}^{o}=$

$\widehat{a}+\widehat{b} U_{t}^{c}$ in the solid line and the corresponding bid and ask bounds on the scaled American puts in two dotted lines. Each panel plots the time series for one company. For AMR, EK, F, GM, and GT, the fitted value from the CDS market almost always falls within the bid-ask range of the American puts, indicating that the two markets are largely integrated. The matching for CTB, DDS, and KBH are weaker.

[Fig. 1 about here.]

\subsection{Non-CDS driven variations in American puts}

At normal market conditions and strike ranges, option values vary strongly with the underlying stock price and the stock return volatility. The option price sensitivities to these two variables are referred to as the option delta and vega, respectively. The joint dependence also makes the option value a convex function of 
the underlying strike price. Yet, we show that as long as there exists a default corridor, the spread between two American puts struck within this corridor creates a pure credit contract, the value of which depends only on the default risk of the company and interest rates, but does not depend explicitly on either the stock price or stock return volatility.

The regression results in Table 3 show that a large proportion of the movements in the American puts $\left(U_{t}^{o}\right)$ can indeed be explained by the variation in the CDS market $\left(U_{t}^{c}\right)$. On the other hand, the regression residuals $\left(u_{t}\right)$ capture the variations in the American puts that are not explained by the CDS variation. These non-CDS driven variations can come either from measurement errors and demand shocks from the options market, or from violations of our model assumptions: The American puts can contain pricing for market risk and hence non-zero delta and vega risk exposures. To test this hypothesis, we regress daily changes in the non-CDS driven variation of the American puts $\left(\mathcal{U}_{t}\right)$ against daily changes in the stock price and stock return volatility measures, respectively,

$$
\Delta u_{t}=a+b \Delta X_{t}+e_{t}
$$

where we consider three variables for $X_{t}$ : the stock price $\left(S_{t}\right)$, stock return realized volatility over the past year $\left(R V_{t}\right)$, and at-the-money option implied volatility $\left(A T M V_{t}\right)$ at the same option expiry date of the American put. The stock price $S_{t}$ is not adjusted for stock splits or dividends and hence match the scale of the option price; the return realized volatility is computed based on log daily returns, $R V_{t}=\sqrt{\sum_{d=1}^{365} r_{t-d}^{2}}$; and the at-the-money implied volatility is obtained by interpolating the OptionMetrics-provided implied volatility on the options of the same maturity across strikes to obtain an estimate at the strike that equals the spot price. We estimate each relation using the generalized methods of moments with the weighting matrix according to Newey and West (1987) with 30 lags.

Table 4 reports the estimation results. When the regressor is daily changes in the stock price, we obtain negative slope (delta) estimates for all eight companies, with seven of them statistically significant.The Rsquared averages around $8 \%$. These results suggest that the American puts either contain a market risk component that our model fails to include or that the stock prices contain credit risk information not present in the CDS market.

When the regressor is changes in the realized return volatility, the slope estimates are largely insignificant for most companies and the R-squares are all close to zero. The only exception is DDS, for which the slope estimate is statistically significant. Nevertheless, the estimate has a negative sign and is hence counter-intuitive. By contrast, when the regressor is at-the-money implied volatility, all slope estimates are positive and statisti- 
cally significant. The R-squares are also relatively high and average around 10\%. Thus, a significant portion (about 10\%) of the non-CDS driven variation of the American puts is due to common movements in the stock option implied volatility surface. This common movements can be due to either market risk variations or option market's perception of credit risk variations. Credit risk not only affects the pricing of far out-of-themoney American puts struck within the default corridor, but also affects option prices across the whole strike and maturity spectrum (Carr and $\mathrm{Wu}(2005))$.

\subsection{Predicting futures options and CDS market movements based on their current deviation}

If the non-CDS driven variation in the American puts $\left(\mathfrak{U}_{t}\right)$ are purely due to measurement errors or shortterm liquidity shocks that will dissipate quickly, we would expect the American put values to revert to its predicted values. Then, the non-CDS driven variation $\mathfrak{u}_{t}$ can be used to predict future movements in the American puts: Positive values of $\mathfrak{U}_{t}$ predict negatively on future American puts and negative values of $\mathfrak{u}_{t}$ predict future increases in the American put value (after adjustment for time decay).

On the other hand, if $\mathfrak{U}_{t}$ also contains common option market movements that reveal credit risk information currently absent from the CDS market, we would expect such information to be reflected in the CDS quotes eventually. In this case, non-CDS driven variation of the American puts $\mathfrak{u}_{t}$ can predict future movements in the CDS market: Positive values of $\mathfrak{u}_{t}$ predict positively on CDS movements and vice versa.

One way to test the two scenarios is through the following error-correction regressions (Engle and Granger (1987)),

$$
\Delta U_{t+\Delta t}^{o}=\alpha^{o}+\beta^{o} \mathfrak{u}_{t}+e_{t+\Delta t}, \quad \Delta U_{t+\Delta t}^{c}=\alpha^{c}+\beta^{c} \mathfrak{u}_{t}+e_{t+\Delta t}
$$

where we use the contemporaneous regression residuals $\left(\mathfrak{U}_{t}\right)$ from equation (35) to predict future movements in the American puts $\left(\Delta U_{t+\Delta t}^{o}\right)$ and the CDS spreads $\left(\Delta U_{t+\Delta t}^{c}\right)$. In the presence of short-term movements in American puts, we would expect a negative slope $\beta^{o}$ on the first predictive regression. In the presence of additional credit risk information in the options market, we would expect a positive slope $\beta^{c}$ on the second predictive regression.

We estimate the predictive regressions in equation (37) using generalized methods of moments over horizons of one day, seven days, and 30 days. Table 5 presents the estimation results. The predictive regressions on American puts (left hand side) generate negative and mostly significant slope estimates at all three forecasting horizons. The R-squares average at 3\%,6.9\%, and $16.2 \%$ at the 1-, 7-, and 30-day horizon, respectively. The 
results suggest that the American put's contemporaneous regression deviation from the CDS market contains a significant transient component that dissipates quickly. Alternatively speaking, the credit risk information flows from the CDS market to the stock options market.

On the other hand, the predictive regressions on the CDS market movements (right hand side) generate less significant results, suggesting that the reverse information flow about the credit risk information is not as strong. The credit risk information is mainly discovered in the CDS market. Nevertheless, for some companies such as AMR, GM, and $\mathrm{KBH}$, the slope estimates on the predictive regressions become significant positive, suggesting that for these stocks, the credit risk information also flow from the American put market to the CDS market.

\section{Concluding remarks}

The literature on strategic default often predicts that a company goes to default strategically well before its firm value falls below its debt. Under these predictions, the stock price stays above a strictly positive barrier prior to default. On the other hand, firm and equity values often experience sudden drops upon default due to deadweight losses such as legal fees and liquidation costs. In this paper, we develop a class of models for the stock price that are consistent with these observations. Prior to default, stock prices are bounded below by a positive constant $B$. After default, the stock prices drops and stays below another constant $A<B$. We refer to the region $[A, B]$ as the default corridor, within which the stock price can never reside. We show that when the default corridor exists, a vertical spread of American put options scaled by the difference in strikes has the same payoff as a standardized credit claim paying one dollar at default if this event occurs before the options expire, and paying zero otherwise. We label this standardized credit insurance contract as the unit recovery claim. The replication of this contract is simple and is robust to the details of the stock price dynamics before and after default. Since the two positions pay off the same amount at the same random time, the replication is also robust to the dynamics of interest rates and default arrival rates.

We use the value of the American put spread to infer the value of the unit recovery claims and compare it to the value estimated from the credit default swap (CDS) market. Collecting data from both markets on eight reference names, we show that the unit recovery claim values estimated from the two markets are similar in magnitude, and show strongly positive co-movements. We also find that the contemporaneous regression deviations between the two series help predict future movements in both markets, especially that 
of the American puts.

Our identified linkage provides fertile ground for future research. On the theoretical side, research effort should be directed towards specifying the trading strategy that should be enacted when arbitrage arises. In particular, there is an issue of how to deal with an unexercised short put in the event of default, particularly when the cost of buying this put is above its exercise value. Research effort should also be directed towards further relaxation of the assumptions. In particular, the effect of random bond recovery rates and (discrete) dividends needs to be addressed. On the empirical side, much work is needed in investigating how the put strikes should be chosen and how to deal with maturity mismatches between the two markets. 


\section{Appendix A. Conditional transitional probability density function}

Under the toy DDD model, conditional on no default up to time $t$, we can rewrite the dynamics in equation (9) as,

$$
S_{t-}=R(0) e^{r t}+[B-R(0)] e^{(r+\lambda) t}+\left(S_{0}-B\right) e^{(r+\lambda) t} G_{t}, \quad t \in[0, T]
$$

Solving for $G_{t}$, we have

$$
G_{t}=\frac{S_{t-}-\left\{R(0) e^{r t}+[B-R(0)] e^{(r+\lambda) t}\right\}}{\left(S_{0}-B\right) e^{(r+\lambda) t}}
$$

Evaluating at $t=T$ leads to

$$
G_{T}=\frac{S_{T-}-\left\{A+[B-R(0)] e^{(r+\lambda) T}\right\}}{\left(S_{0}-B\right) e^{(r+\lambda) T}} .
$$

Taking the ratio of (A3) to (A2) implies

$$
\frac{G_{T}}{G_{t}}=\frac{\left(S_{T-}-A\right) e^{-(r+\lambda)(T-t)}-[B-R(0)] e^{(r+\lambda) t}}{S_{t-}-\left\{R(0) e^{r t}+[B-R(0)] e^{(r+\lambda) t}\right\}} \equiv h\left(S_{T-}, S_{t-}\right) .
$$

Since $\frac{G_{T}}{G_{t}}=e^{\sigma\left(W_{T}-W_{t}\right)-\frac{1}{2} \sigma^{2}(T-t)}$, the ratio is lognormally distributed:

$$
\mathbb{Q}\left\{\frac{G_{T}}{G_{t}} \in d h\right\}=\frac{1}{\sqrt{2 \pi \sigma^{2}(T-t)} h} e^{-\frac{\ln h+\frac{1}{2} \sigma^{2}(T-t)}{2 \sigma^{2}(T-t)}} d h \equiv \ell(h) d h .
$$

Let $B(t) \equiv R(0) e^{r t}+[B-R(0)] e^{(r+\lambda) t}$. For $K>B(T)$ and $S>B(t)$, the transition probability density conditional on surviving to $T$ is

$$
\begin{aligned}
\mathbb{Q}\left\{S_{T} \in d K \mid S_{t}=S, N_{T}=0\right\} & =\mathbb{Q}\left\{\frac{G_{T}}{G_{t}} \in d h(K, S)\right\} \frac{\partial h(K, S)}{\partial K} d K \\
& =\ell(h(K, S)) \frac{e^{-(r+\lambda)(T-t)}}{S-\left\{R(0) e^{r t}+[B-R(0)] e^{(r+\lambda) t}\right\}} d K \\
& =\frac{1}{\sqrt{2 \pi \sigma^{2}(T-t)}} \exp \left[-\frac{\ln h(K, S)+\frac{1}{2} \sigma^{2}(T-t)}{2 \sigma^{2}(T-t)}\right] \frac{1}{K-R-[B-R(0)] e^{(r+\lambda) T}} .
\end{aligned}
$$




\section{References}

Acharya, V. V., Carpenter, J., 2002. Corporate bond valuation and hedging with stochastic interest rates and endogenous bankruptcy. Review of Financial Studies 15, 1355-1383.

Altman, E. I., Brady, B., Resti, A., Sironi, A., 2005. The link between default and recovery rates: Theory, empirical evidence and implications. Journal of Business 78, 2203-2228.

Anderson, R. W., Sundaresan, S., 1996. Design and valuation of debt contracts. Review of Financial Studies 9, 37-68.

Anderson, R. W., Sundaresan, S., Tychon, P., 1996. Strategic analysis of contingent claims. European Economic Review $40,871-881$.

Aunon-Nerin, D., Cossin, D., Hricko, T., Huang, Z., 2002. Exploring for the determinants of credit risk in credit default swap transaction data: Is fixed-income markets information sufficient to evaluate credit risk. FAME Research Paper 65 University of Lausanne.

Bakshi, G., Madan, D., Zhang, F., 2006. Investigating the role of systematic and firm-specific factors in default risk: Lessons from empirically evaluating credit risk models. Journal of Business 79, 1955-1987.

Bangia, A., Diebold, F. X., Kronimus, A., Schagen, C., Schuermann, T., 2002. Ratings migration and the business cycle, with application to credit portfolio stress testing. Journal of Banking and Finance 26, 445-474.

Berndt, A., Ostrovnaya, A., 2007. Information flow between credit default swap, option and equity markets. Working paper. Carnegie Mellon University.

Bevan, A., Garzarelli, F., 2000. Corporate bond spreads and the business cycle: Introducing gs-spread. Journal of Fixed Income 9, 8-18.

Bhamra, H. S., Kuehn, L.-A., Strebulaev, I. A., 2007. The levered equity risk premium and credit spreads: A unified framework. Working paper. University of British Columbia and Stanford University.

Black, F., Cox, J. C., 1976. Valuing corporate securities: Some effects of bond indenture provisions. Journal of Finance $31,351-367$.

Black, F., Scholes, M., 1973. The pricing of options and corporate liabilities. Journal of Political Economy 81, 637-654.

Briys, E., de Varenne, F., 1997. Valuing risky fixed rate debt: An extension. Journal of Financial and Quantitative Analysis 32, 239-248.

Broadie, M., Chernov, M., Sundaresan, S., 2007. Optimal debt and equity values in the presence of chapter 7 and chapter 11. Journal of Finance 62, 1341-1377.

Buraschi, A., Trojani, F., AndreaVedolin, 2007. The joint behavior of credit spreads, stock options and equity returns when investors disagree. Working paper. Imperial College and University of St. Gallen. 
Cao, C., Yu, F., Zhong, Z., 2007. The information content of option-implied volatility for credit default swap valuation. Working paper. Pennsylvania State University and Michigan State University.

Capmbell, J. Y., Taksler, G. B., 2003. Equity volatility and corporate bond yields. Journal of Finance 63, 2321-2349.

Carey, M., 1998. Credit risk in private debt portfolios. Journal of Finance 53, 1363-1387.

Carey, M., Gordy, M. B., 2007. The bank as grim reaper: Debt composition and recoveries on defaulted debt. Working paper. Board of Governors of the Federal Reserve System.

Carr, P., Flesaker, B., 2007. Robust replication of default contingent claims. Working paper. Bloomberg LP.

Carr, P., Laurence, P., 2006. Implied volatility approximation in the black-scholes model with possible jump to default. Working paper. New York University and University of Rome 1.

Carr, P., Linetsky, V., 2006. A jump to default extended cev model: An application of bessel processes. Finance and Stochastics 10, 303-330.

Carr, P., Wu, L., 2005. Stock options and credit default swaps: A joint framework for valuation and estimation. Working paper. New York University and Baruch College.

Chen, L., Collin-Dufresne, P., Goldstein, R. S., 2008. On the relation between the credit spread puzzle and the equity premium puzzle. Review of Financial Studies forthcoming.

Collin-Dufresne, P., Goldstein, R. S., Martin, J. S., 2001. The determinants of credit spread changes. Journal of Finance $56,2177-2207$.

Consigli, G., 2004. Credit default swaps and equity volatility: Theoretical modelling and market evidence. Working paper. University Ca'Foscari.

Cremers, M., Driessen, J., Maenhout, P. J., 2008. Explaining the level of credit spreads: Option-implied jump risk premia in a firm value model. Review of Financial Studies forthcoming.

Cremers, M., Driessen, J., Maenhout, P. J., Weinbaum, D., 2004. Individual stock options and credit spreads. Yale ICF Working Paper 04-14 Yale School of Management.

Delianedis, G., Geske, R., 2001. The components of corporate credit spreads: Default, recovery, tax, jumps, liquidity, and market factors. Working paper. UCLA.

Duffie, D., Lando, D., 2001. Term structure of credit spreads with incomplete accounting information. Econometrica 9, 633-664.

Elton, E. J., Gruber, M. J., Agrawal, D., Mann, C., 2001. Explaining the rate spread on corporate bonds. Journal of Finance 56, 247-277.

Engle, R. F., Granger, C. W., 1987. Cointegration and error correction: Representation, estimation and testing. Econometrica 55, 251-276. 
Ericsson, J., Jacobs, K., Oviedo-Helfenberger, R., 2004. The determinants of credit default swap premia. Working paper. McGill University.

Fan, H., Sundaresan, S. M., 2000. Debt valuation, renegotiation and optimal dividend policy. Review of Financial Studies 13, 1057-1099.

Frye, J., 2000. Depressing recoveries. Risk October, 108-111.

Garbade, K. D., 1999. Managerial discretion and the contingent valuation of corporate securities. Journal of Derivatives $6,65-76$.

Geske, R., 1977. The valuation of corporate liabilities as compound options. Journal of Financial and Quantitative Analysis 12, 541-552.

Goldstein, R., Ju, N., Leland, H., 2001. An ebit-based model of dynamic capital structure. Journal of Business 74, 483-512.

Hackbarth, D., Hennessy, C. A., Leland, H. E., 2007. Can the trade-off theory explain debt structure. Review of Financial Studies 20, 1389-1428.

Hilscher, J., 2004. Is the corporate bond market forward looking?. Working paper. Harvard University.

Ho, T. S., Singer, R. F., 1982. Bond indenture provisions and the risk of corporate debt. Journal of Financial Economics $10,375-406$.

Huang, J.-z., Huang, M., 2003. How much of the corporate-Treasury yield spread is due to credit risk?. Working paper. Penn State University.

Hull, J., Nelken, I., White, A., 2004. Mertons model, credit risk and volatility skews. Journal of Credit Risk 1, 8-23.

Kim, I. J., Ramaswamy, K., Sundaresan, S., 1993. Does default risk in coupons affect the valuation of corporate bonds?: A contingent claims model. Financial Management 22, 117-131.

Le, A., 2007. Separating the components of default risks: A derivative-based approach. Working paper. New York University.

Leland, H. E., 1994. Risky debt, bond covenants and optimal capital structure. Journal of Finance 49, 1213-1252.

Leland, H. E., 1998. Agency costs, risk management, and capital structure. Journal of Finance 53, 1213-1243.

Leland, H. E., Toft, K. B., 1996. Optimal capital structure, endogenous bankruptcy and the term structure of credit spreads. Journal of Finance 51, 987-1019.

Longstaff, F. A., Schwartz, E. S., 1995. A simple approach to valuing risky fixed and floating rate debt. Journal of Finance 50, 789-819.

Mella-Barral, P., Perraudin, W., 1997. Strategic debt service. Journal of Finance 52, 531-566. 
Merton, R. C., 1973. Theory of rational option pricing. Bell Journal of Economics and Management Science 4, $141-183$.

Merton, R. C., 1974. On the pricing of corporate debt: The risk structure of interest rates. Journal of Finance 29, 449-470.

Merton, R. C., 1976. Option pricing when underlying stock returns are discontinuous. Journal of Financial Economics $3,125-144$.

Newey, W. K., West, K. D., 1987. A simple, positive semi-definite, heteroskedasticity and autocorrelation consistent covariance matrix. Econometrica 55, 703-708.

Pedrosa, M., Roll, R., 1998. Systematic risk in corporate bond yields. Journal of Fixed Income 8, 7-26.

Ronn, E. I., Verma, A. K., 1986. Pricing risk-adjusted deposit insurance: An option based model. Journal of Finance 41, $871-895$.

Rubinstein, M., 1983. Displaced diffusion option pricing. Journal of Finance 38, 213-217.

Titman, S., Torous, W., 1989. Valuing commercial mortgages: An empirical investigation of the contingent claim approach to pricing risky debt. Journal of Finance 44, 345-373.

Vassalou, M., Xing, Y., 2004. Default risk in equity returns. Journal of Finance 59, 831-868.

Wu, L., Zhang, F. X., 2008. A no-arbitrage analysis of economic determinants of the credit spread term structure. Management Science forthcoming.

Zhang, B., Zhou, H., Zhu, H., 2006. Explaining credit default swap spreads with the equity volatility and jump risks of individual firms. Working paper. Fitch Ratings Inc. and Federal Reserve Board and Bank for International Settlements.

Zhou, C., 2001. The term structure of credit spreads with jump risk. Journal of Banking and Finance 25, $2015-2040$. 
Table 1

List of companies used in our study

Entries list the equity ticker, cusip, and the name of the companies that are used in our study.

\begin{tabular}{lll}
\hline Equity Ticker & Cusip Number & Company Name \\
& & \\
AMR & 00176510 & AMR Corp \\
CTB & 21683110 & Cooper Tire \& Ribber \\
DDS & 25406710 & Dillard's Inc. \\
EK & 27746110 & Eastman Kodak Co \\
F & 34537086 & Ford Motor Co \\
GM & 37044210 & General Motors Corp \\
GT & 38255010 & Goodyear Tire \& Rubber Co \\
KBH & 48666 K10 & KB Home \\
& & \\
\hline
\end{tabular}

Table 2

Summary statistics of unit recovery claims

Entries report the mean, standard deviation (Std), minimum (Min), maximum (Max), and daily autocorrelation (Auto) of unit recovery claim values extracted for the American put options $\left(U^{o}\right)$ and from CDS markets $\left(U^{c}\right)$. The last column reports the cross-correlation $(\rho)$ of the two corresponding time series. The last row reports the average of the statistics across the eight companies.

\begin{tabular}{|c|c|c|c|c|c|c|c|c|c|c|c|}
\hline \multirow[t]{2}{*}{ Ticker } & \multicolumn{5}{|c|}{$U^{c}$} & \multicolumn{5}{|c|}{$U^{o}$} & \multirow[t]{2}{*}{$\rho$} \\
\hline & Mean & $\overline{\text { Std }}$ & Min & Max & Auto & Mean & $\overline{\text { Std }}$ & Min & Max & Auto & \\
\hline AMR & 0.265 & 0.167 & 0.052 & 0.573 & 0.995 & 0.116 & 0.073 & 0.020 & 0.300 & 0.982 & 0.933 \\
\hline СТВ & 0.052 & 0.042 & 0.005 & 0.218 & 0.993 & 0.087 & 0.039 & 0.020 & 0.205 & 0.964 & 0.369 \\
\hline DDS & 0.032 & 0.018 & 0.009 & 0.078 & 0.990 & 0.063 & 0.026 & 0.022 & 0.130 & 0.981 & 0.709 \\
\hline EK & 0.037 & 0.019 & 0.011 & 0.083 & 0.989 & 0.043 & 0.019 & 0.013 & 0.090 & 0.969 & 0.869 \\
\hline F & 0.136 & 0.066 & 0.035 & 0.275 & 0.989 & 0.103 & 0.044 & 0.020 & 0.235 & 0.967 & 0.806 \\
\hline GM & 0.165 & 0.106 & 0.049 & 0.408 & 0.994 & 0.085 & 0.060 & 0.030 & 0.270 & 0.968 & 0.941 \\
\hline GT & 0.073 & 0.034 & 0.011 & 0.148 & 0.986 & 0.075 & 0.034 & 0.013 & 0.175 & 0.970 & 0.869 \\
\hline $\mathrm{KBH}$ & 0.026 & 0.010 & 0.008 & 0.047 & 0.984 & 0.048 & 0.038 & 0.010 & 0.160 & 0.983 & 0.774 \\
\hline Average & 0.098 & 0.058 & 0.023 & 0.229 & 0.990 & 0.077 & 0.042 & 0.019 & 0.196 & 0.973 & 0.784 \\
\hline
\end{tabular}


Table 3

Explaining equity American puts with CDS market variation

Entries on the left hand side report the coefficient estimates and $t$-statistics (in parentheses) of the following equation,

$$
U_{t}^{o}=a+b U_{t}^{c}+\mathcal{u}_{t}
$$

where we regress the scaled American put value, $U_{t}^{o}=P_{t}(K) / K$ on the unit recovery claim value estimated from the corresponding CDS spreads. The relations are estimated with generalized methods of moments with the weighting matrix built according to Newey and West (1987) with 60 lags. The $t$-statistics are computed against the null hypothesis of $a=0$ and $b=1$, respectively. Entries on the right hand side report the Rsquared of the regression $\left(R^{2}\right)$, and the daily autocorrelation (Auto), minimum (Min), and maximum (Max) of the regression residual $\mathfrak{U}_{t}$. The last row reports the average of the statistics across the eight companies.

\begin{tabular}{lrrrrrrrr}
\hline \multirow{2}{*}{ Ticker } & \multicolumn{2}{c}{$a$} & \multicolumn{2}{c}{$b$} & $R^{2}$ & Auto & Min & Max \\
& & & & & & & & \\
\hline AMR & 0.008 & $(1.42)$ & 0.406 & $(-17.32)$ & 0.870 & 0.894 & -0.071 & 0.083 \\
CTB & 0.069 & $(4.53)$ & 0.343 & $(-4.47)$ & 0.136 & 0.961 & -0.060 & 0.082 \\
DDS & 0.029 & $(3.55)$ & 1.049 & $(0.24)$ & 0.502 & 0.970 & -0.043 & 0.038 \\
EK & 0.012 & $(3.77)$ & 0.847 & $(-2.44)$ & 0.755 & 0.894 & -0.036 & 0.027 \\
F & 0.030 & $(2.44)$ & 0.531 & $(-6.71)$ & 0.650 & 0.931 & -0.053 & 0.084 \\
GM & -0.004 & $(-0.64)$ & 0.539 & $(-10.44)$ & 0.885 & 0.774 & -0.050 & 0.093 \\
GT & 0.010 & $(1.88)$ & 0.890 & $(-1.09)$ & 0.756 & 0.925 & -0.041 & 0.067 \\
KBH & -0.025 & $(-2.03)$ & 2.858 & $(2.85)$ & 0.599 & 0.966 & -0.090 & 0.063 \\
Average & 0.016 & $(1.87)$ & 0.933 & $(-4.92)$ & 0.644 & 0.914 & -0.055 & 0.067 \\
& & & & & & & & \\
\hline
\end{tabular}


Table 4

Explain non-CDS driven variation in American puts

Entries report the estimates and $t$-statistics (in parentheses) of the following regression,

$$
\Delta \mathfrak{u}_{t}=a+b \Delta X_{t}+e_{t},
$$

for each company, where $\mathfrak{U}_{t}$ denotes the residual by regressing $U_{t}^{o}$ on $U_{t}^{c}$ and thus captures the value variations of American put that cannot be explained by the corresponding CDS contract. The explanatory variables $X$ include the stock price $S_{t}$, one-year realized volatility $R V_{t}$, and at-the-money implied volatility $\left(A T M V_{t}\right)$, respectively. We perform the regression on daily changes using generalized methods of moments with the weighting matrix built according to Newey and West (1987) with 30 lags.

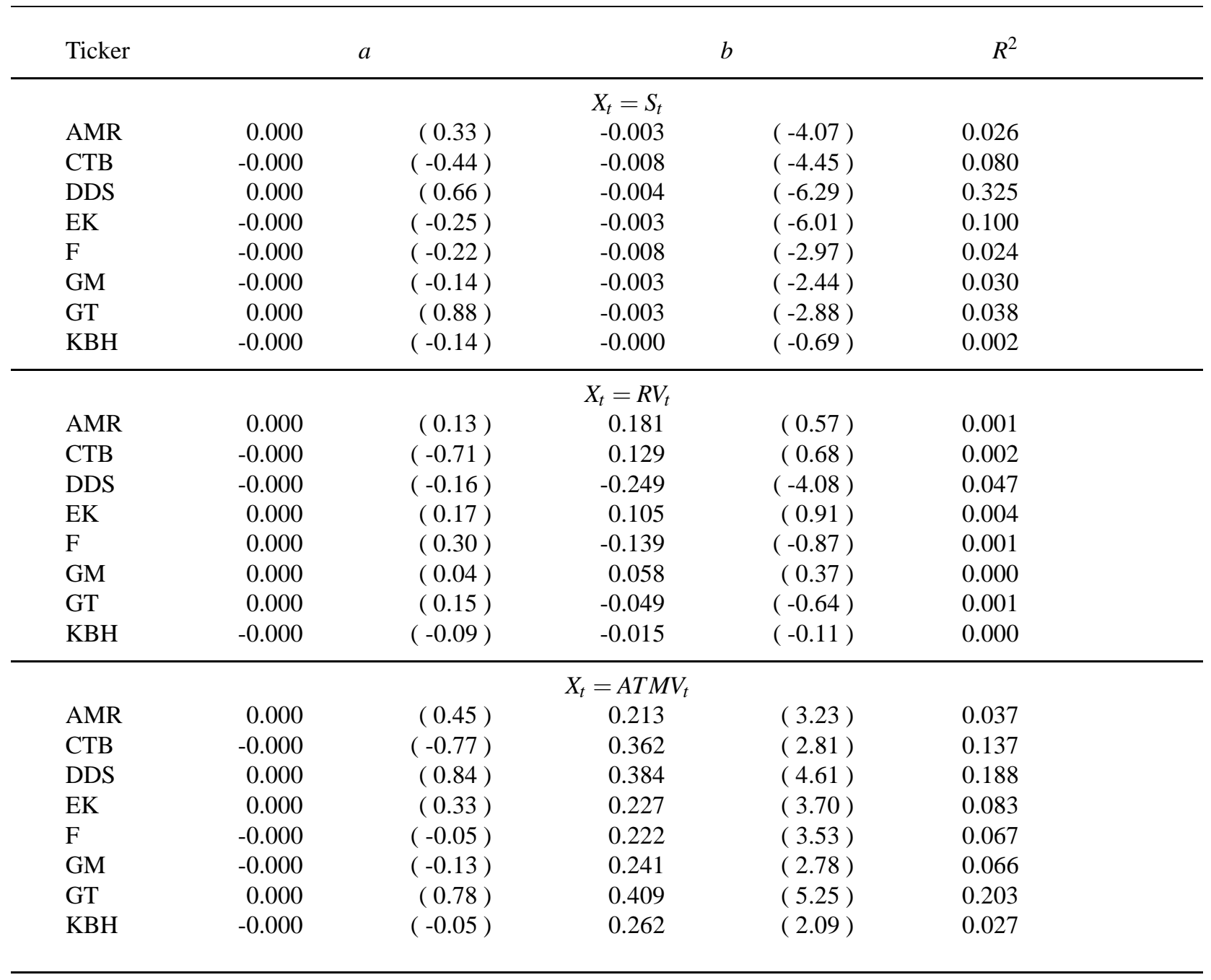


Table 5

Predicting future movements on unit recovery claims based on cross-market deviations in unit recovery claim values

Entries report the estimates, Newey-West $t$-statistics (in parentheses), and R-squares $\left(R^{2}\right)$ from the following regressions that predict future movements in American puts and CDS spreads based on their current regression deviations $\left(\mathfrak{U}_{t}\right)$,

$$
\Delta U_{t+\Delta t}^{o}=\alpha^{o}+\beta^{o} \mathfrak{U}_{t}+e_{t+\Delta t}^{o}, \quad \Delta U_{t+\Delta t}^{c}=\alpha^{c}+\beta^{c} \mathfrak{U}_{t}+e_{t+\Delta t}^{c},
$$

where forecasting horizons $(\Delta t)$ are at one, seven, and 30 days.

\begin{tabular}{|c|c|c|c|c|c|c|c|c|c|c|}
\hline \multirow[t]{2}{*}{ Ticker } & \multicolumn{5}{|c|}{$\Delta U_{t+\Delta t}^{o}=\alpha^{o}+\beta^{o} \mathfrak{u}_{t}+e_{t+\Delta t}^{o}$} & \multicolumn{5}{|c|}{$\Delta U_{t+\Delta t}^{c}=\alpha^{c}+\beta^{c} \mathcal{U}_{t}+e_{t+\Delta t}^{c}$} \\
\hline & \multicolumn{2}{|r|}{$\alpha^{o}$} & \multicolumn{2}{|c|}{$\beta^{o}$} & $R^{2}$ & \multicolumn{2}{|r|}{$\alpha^{c}$} & \multicolumn{2}{|c|}{$\beta^{c}$} & \multirow[t]{2}{*}{$R^{2}$} \\
\hline & & & & & $\Delta t$ & day & & & & \\
\hline AMR & -0.001 & $(-1.21)$ & -0.070 & $(-2.77)$ & 0.033 & -0.001 & $(-2.20)$ & 0.037 & ( 1.94 ) & 0.012 \\
\hline СТВ & 0.000 & $(0.47)$ & -0.015 & $(-1.44)$ & 0.005 & -0.000 & $(-0.35)$ & -0.004 & $(-0.42)$ & 0.001 \\
\hline DDS & -0.000 & $(-1.36)$ & -0.021 & $(-2.64)$ & 0.012 & -0.000 & $(-1.25)$ & -0.001 & $(-0.38)$ & 0.000 \\
\hline EK & -0.000 & $(-0.04)$ & -0.093 & $(-4.30)$ & 0.052 & -0.000 & $(-0.82)$ & 0.014 & $(2.13)$ & 0.005 \\
\hline $\mathrm{F}$ & -0.000 & $(-0.11)$ & -0.079 & $(-2.90)$ & 0.050 & -0.000 & $(-0.68)$ & -0.028 & $(-2.72)$ & 0.015 \\
\hline GM & -0.000 & $(-0.42)$ & -0.127 & $(-3.47)$ & 0.054 & -0.000 & $(-0.46)$ & 0.051 & $(1.70)$ & 0.019 \\
\hline GT & -0.000 & $(-0.81)$ & -0.065 & $(-3.65)$ & 0.033 & -0.000 & $(-1.41)$ & 0.003 & $(0.22)$ & 0.000 \\
\hline $\mathrm{KBH}$ & -0.000 & $(-0.78)$ & -0.007 & $(-1.22)$ & 0.002 & -0.000 & $(-0.43)$ & 0.007 & ( 2.06$)$ & 0.013 \\
\hline \multirow[t]{2}{*}{ Average } & -0.000 & $(-0.53)$ & -0.060 & $(-2.80)$ & 0.030 & -0.000 & $(-0.95)$ & 0.010 & $(0.57)$ & 0.008 \\
\hline & \multicolumn{10}{|c|}{$\Delta t=7$ days } \\
\hline AMR & -0.003 & $(-1.68)$ & -0.174 & $(-2.48)$ & 0.078 & -0.006 & $(-2.38)$ & 0.166 & ( 1.70$)$ & 0.036 \\
\hline СТВ & 0.001 & $(0.48)$ & -0.056 & $(-1.19)$ & 0.015 & -0.000 & $(-0.32)$ & -0.004 & $(-0.08)$ & 0.000 \\
\hline DDS & -0.001 & $(-1.66)$ & -0.087 & $(-2.54)$ & 0.051 & -0.001 & $(-1.46)$ & -0.013 & $(-0.52)$ & 0.003 \\
\hline EK & 0.000 & $(0.15)$ & -0.296 & $(-5.90)$ & 0.170 & -0.001 & $(-0.85)$ & 0.021 & $(0.59)$ & 0.001 \\
\hline $\mathrm{F}$ & 0.000 & $(0.15)$ & -0.204 & $(-2.64)$ & 0.113 & -0.001 & $(-0.65)$ & -0.144 & $(-2.52)$ & 0.039 \\
\hline GM & -0.000 & $(-0.11)$ & -0.171 & $(-2.74)$ & 0.043 & -0.001 & $(-0.45)$ & 0.213 & $(1.62)$ & 0.035 \\
\hline GT & -0.001 & $(-0.93)$ & -0.188 & $(-2.48)$ & 0.079 & -0.002 & $(-1.45)$ & -0.015 & $(-0.19)$ & 0.001 \\
\hline $\mathrm{KBH}$ & -0.000 & $(-0.54)$ & -0.002 & $(-0.07)$ & 0.000 & -0.000 & $(-0.52)$ & 0.053 & $(2.76)$ & 0.075 \\
\hline \multirow[t]{2}{*}{ Average } & -0.001 & $(-0.52)$ & -0.147 & $(-2.51)$ & 0.069 & -0.002 & $(-1.01)$ & 0.035 & $(0.42)$ & 0.024 \\
\hline & \multicolumn{10}{|c|}{$\Delta t=30$ days } \\
\hline AMR & -0.010 & $(-2.10)$ & -0.594 & $(-3.69)$ & 0.240 & -0.029 & $(-3.28)$ & -0.333 & $(-1.30)$ & 0.031 \\
\hline СТВ & 0.002 & $(0.44)$ & -0.143 & $(-1.06)$ & 0.028 & -0.002 & $(-0.41)$ & -0.010 & $(-0.09)$ & 0.000 \\
\hline DDS & -0.004 & $(-2.20)$ & -0.288 & $(-3.13)$ & 0.161 & -0.002 & $(-1.37)$ & -0.067 & $(-0.84)$ & 0.017 \\
\hline EK & -0.000 & $(-0.18)$ & -0.963 & $(-9.42)$ & 0.415 & -0.002 & $(-1.01)$ & -0.177 & $(-1.26)$ & 0.020 \\
\hline $\mathrm{F}$ & -0.000 & $(-0.00)$ & -0.583 & $(-3.34)$ & 0.234 & -0.005 & $(-0.71)$ & -0.487 & $(-2.62)$ & 0.095 \\
\hline GM & -0.001 & $(-0.17)$ & -0.241 & $(-1.08)$ & 0.023 & -0.006 & $(-0.52)$ & 0.724 & ( 1.73 ) & 0.064 \\
\hline GT & -0.005 & $(-1.36)$ & -0.598 & $(-2.29)$ & 0.186 & -0.007 & $(-1.86)$ & -0.133 & $(-0.65)$ & 0.011 \\
\hline $\mathrm{KBH}$ & -0.002 & $(-1.10)$ & 0.046 & $(0.55)$ & 0.008 & -0.001 & $(-0.38)$ & 0.175 & (3.77) & 0.171 \\
\hline Average & -0.003 & $(-0.83)$ & -0.421 & $(-2.93)$ & 0.162 & -0.007 & $(-1.19)$ & -0.038 & $(-0.16)$ & 0.051 \\
\hline
\end{tabular}



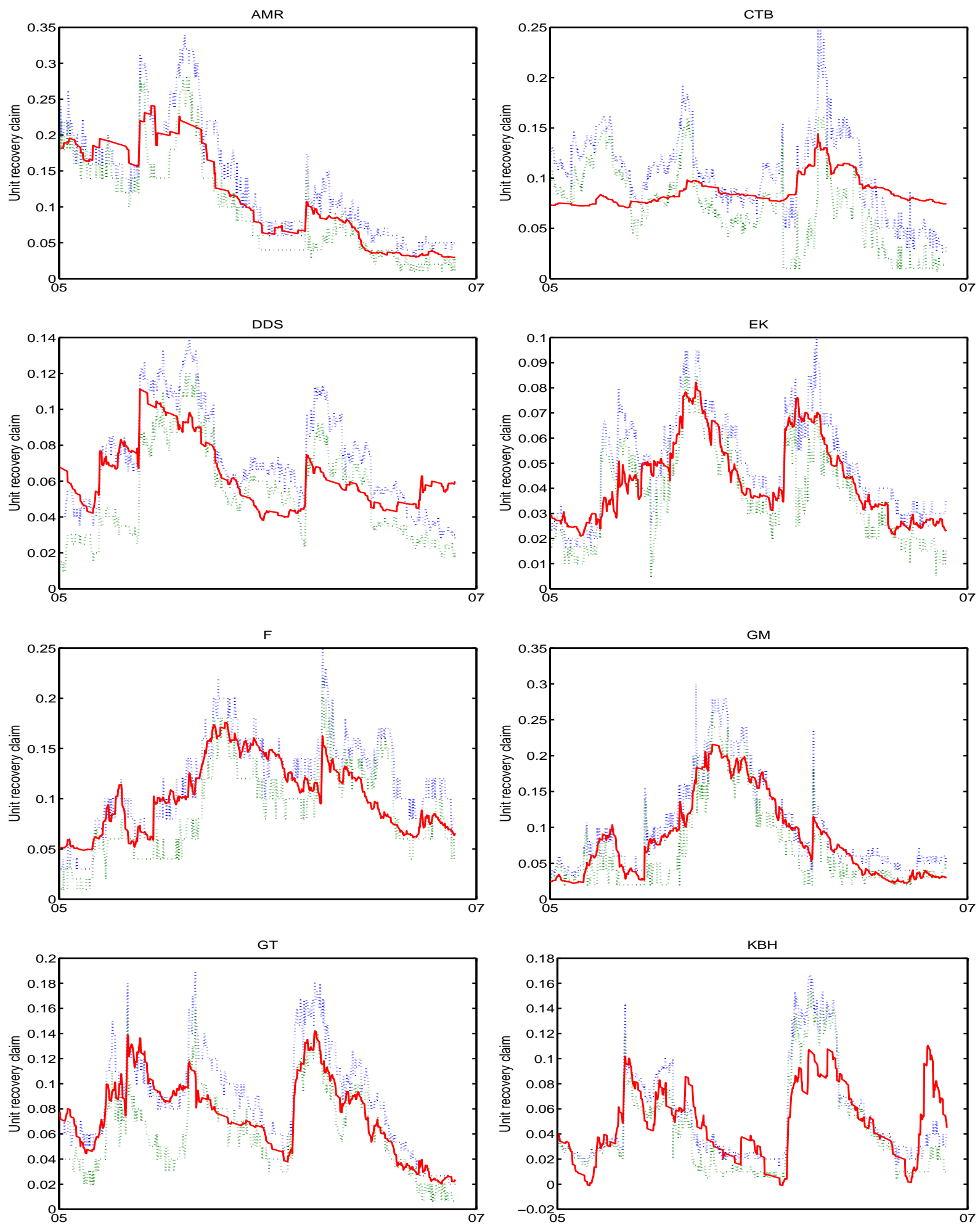

Fig. 1. Time series of unit recovery claims and bid-ask bounds from American puts.

The solid lines are the time series of the unit recovery values constructed from the American puts and explained by the CDS market variation. The two dashed lines are the bid-ask bounds on the American puts. 